\title{
Modulated Model Predictive Speed Control for PMSM Drives
}

\author{
Cristian Garcia and Jose Rodriguez Shafiq Odhano and Pericle Zanchetta \\ Dept. of Engineering \\ Universidad Andres Bello \\ Santiago, Chile \\ cristian.garcia@unab.cl \\ jose.rodriguez@unab.cl \\ Dept. of Elec. and Electron. Eng. \\ University of Nottingham \\ Nottingham, UK \\ shafiq.odhano@nottingham.ac.uk \\ pericle.zanchetta@nottingham.ac.uk
}

S. Alireza Davari

Faculty of Electrical Engineering

Shahid Rajaee Teacher Training University

Tehran, Iran

davari@sru.ac.ir

\begin{abstract}
Model predictive control (MPC) presents important advantages in the control of the power converter and drives such as, fast dynamic response and capability to include nonlinear constrains. These have positioned MPC as a powerful and realistic control strategy, however, it also has disadvantages such as variable switching frequency and parameter sensitivity. This paper applied a modulated model predictive speed control that guarantees a fix switching frequency and, thanks to disturbance compensation, robustness to parameters variation. The strategy is validated and compared to finite set model predictive speed control through simulation results.
\end{abstract}

Index Terms-Model Predictive Control, variable speed drives, dead-beat control.

\section{INTRODUCTION}

Finite set model predictive control (FS-MPC) has positioned itself as a feasible strategy for many power electronic systems [1]. FS-MPC's principle consist in predicting the behavior of the system based on the mathematical model and selecting in a cost function the future state of the power converter that achieves the best performance. This is typically measured as reference tracking. The capacity to include various control objectives and manage non-lineal systems are attractive advantages, [2], [3]. That is why FS-MPC has been successfully implemented in several power converter topologies such as: neutral point clamped converters [4], cascade H-bridge converters [5], matrix converters [6], flying capacitors converters [7], threephase two-level inverter [2], multilevel converters [8] and many others.

FS-MPC has been widely implemented in electrical drives, [9], [10]. Typically, the model predictive control (MPC) is used in the electrical sub-system, controlling the mechanical subsystem usually with a linear controller [9], [11]. In recent works full predictive speed control has been proposed [12][15]. However, these works consider complex cost functions. A simple full finite set model predictive speed control (FSMPSC) has been proposed in [16] for the control of a permanent magnet synchronous machine (PMSM), achieving successful results. Nevertheless, due to the FS-MPC nature, it has a spread switching harmonic spectrum.

FS-MPC does not guaranteed the same number of semiconductor commutation in a fixed period. For this reason,

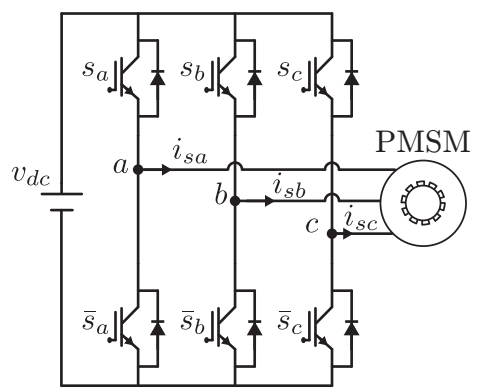

(a)

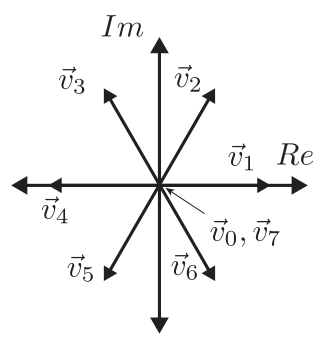

(b)
Fig. 1. Two level voltage source inverter (2L-VSI). (a) Power circuit; (b) Voltage vectors.

its switching harmonic spectrum is spread. This entails, among other problems, difficulties in filter and thermal design [17]. It is for these reasons that different modulated model predictive strategies have been proposed to achieve a fixed switching frequency, [18]-[21].

This paper proposes a modulated model predictive speed control (MMPSC). The proposed control strategy achieves a good dynamic and steady-state behavior, with a fix switching frequency, without weighting factors and without steady-state speed tracking error.

\section{DRIVE MODEL}

The proposed modulated model predictive control strategy is implemented for a permanent-magnet synchronous machine (PMSM) fed by a two-level voltage source inverter (2L-VSI). This section presents the mathematical model of the 2L-VSI and the PMSM.

\section{A. Power Converter}

The converter generates the voltage to feed the stator terminals of the machine, as shown in Fig. 1(a). The 2LVSI generates eight voltage vectors, six active vectors and two zero vectors, as it is shown in Fig. 1(b). At any instant of time, the voltage vector of the power converter in a stationary $\alpha \beta$-frame are,

$$
\mathbf{v}_{s_{\alpha \beta}}=V_{d c} \cdot \frac{2}{3}\left[1 e^{j \frac{2 \pi}{3}} e^{j \frac{4 \pi}{3}}\right] \cdot \mathbf{S},
$$




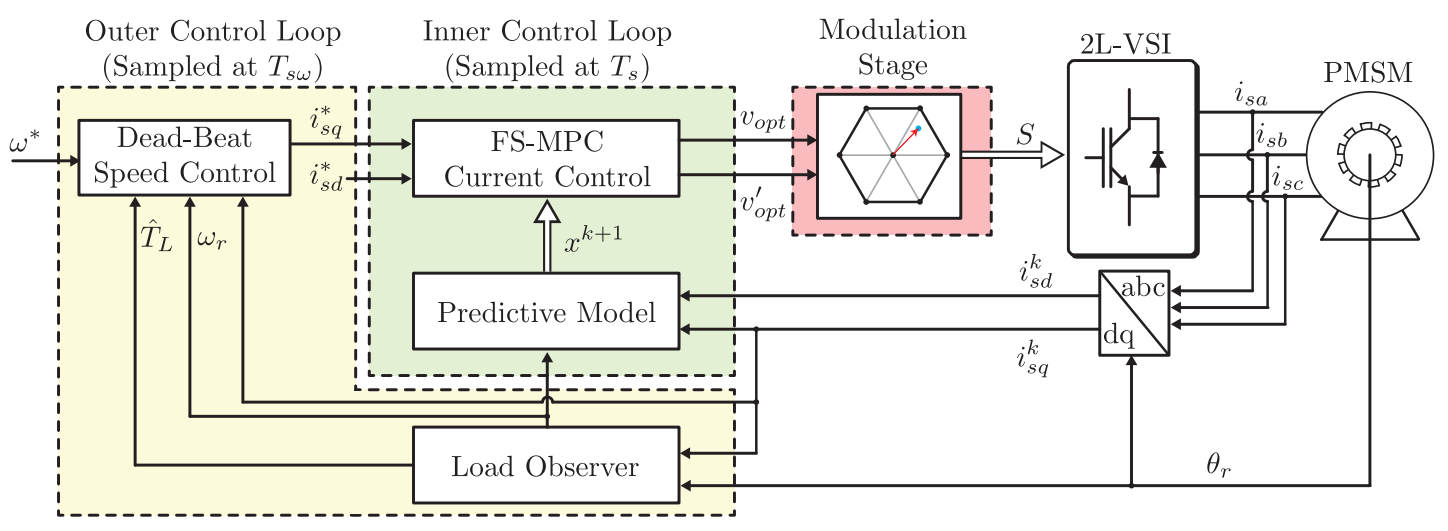

Fig. 2. Scheme of Modulated Model Predictive Speed Control of a PMSM.

where $V_{d c}$ is the dc-link voltage and $\mathbf{S}=\left[\begin{array}{lll}S_{a} & S_{b} & S_{c}\end{array}\right]^{T}$ are the switching state of the converter.

Then, the power converter voltage in a synchronous $d q$ frame oriented with the rotor angle $\theta_{r}$ of the PMSM is,

$$
\mathbf{v}_{s}=\mathbf{v}_{s_{\alpha \beta}} \cdot e^{-j \theta_{r}} .
$$

\section{B. Permanent Magnet Synchronous Machine}

The model of the PMSM in a synchronous $d q$-frame oriented with the rotor position angle $\theta_{r}$ is the following,

$$
\dot{\mathbf{x}}=f(\mathbf{x}, \mathbf{u}),
$$

where,

$$
f(\cdot)=\left(\begin{array}{c}
-\frac{R_{s}}{L_{s}} i_{s d}+\omega_{r} i_{s q}+\frac{1}{L_{s}} v_{s d} \\
-\omega_{r} i_{s d}-\frac{R_{s}}{L_{s}} i_{s q}-\frac{\psi_{m}}{L_{s}} \omega_{r}+\frac{1}{L_{s}} v_{s q} \\
\frac{3}{2 J_{m}} \psi_{m} p^{2} i_{s q}-\frac{B_{m}}{J_{m}} \omega_{r} \\
\omega_{r}
\end{array}\right),
$$

and,

$$
\begin{aligned}
& \mathbf{x}=\left[\begin{array}{llll}
i_{s d} & i_{s q} & \omega_{r} & \theta_{r}
\end{array}\right]^{T}, \\
& \mathbf{u}=\left[\begin{array}{ll}
v_{s d} & v_{s q}
\end{array}\right]^{T} .
\end{aligned}
$$

The parameters of the machine are $R_{s}$ stator resistor, $L_{s}$ stator inductance, $\psi_{m}$ the magnitude of the flux generated by the rotor magnet, $p$ number of pole pairs, $J_{m}$ inertia and $B_{m}$ the friction of the machine. The values of these parameters are shown in the Table I.

\section{Proposed Control Strategy}

The proposed control strategy takes the FS-MPSC concept [16], where a full predictive speed control is achieved, and tries to solve the problem of spread switching harmonic spectrum and ripple using a modulated model predictive control. The control strategy scheme is presented in Fig. 2. This is composed by three main stages:

- Outer control loop: it corresponds to the control of the mechanical subsystem of the machine. The objective is to achieve a good tracking of the speed reference. For that, this control loop used the mechanical model to determinate an adequate quadrature stator current reference. Because the mechanical model requires the load torque for an accurate estimation of the speed, a Kalman filter is uses as disturbance observer for torque estimation.

- Inner control loop: this stage achieves the control of the currents in the electrical subsystem. In this case, the proposed control strategy uses a cost function to determinate the two active vectors whit minimum current error. These vectors will be used in the next modulation stage.

- Modulation control: it receives the two active vectors previously calculated and, by solving a system of equations, determines the duration for these two active vectors and the zero vector that must be applied to achieve the control objective.

The stages mentioned above will be described in more detail below.

\section{A. Outer Control Loop}

This outer loop uses a predictive dead-beat control to establish a quadrature stator current reference starting from the mechanical equation. The following equation is considered:

$$
J_{m} \frac{d \omega_{m}}{d t}=T_{e}-T_{L}-B_{m} \omega_{m}
$$

where $\omega_{m}$ is the mechanical speed, $T_{e}$ is the electrical torque of the PMSM and $T_{L}$ is the load torque. Considering that the electrical torque of the PMSM is,

$$
T_{e}=\frac{3}{2} p \psi_{m} \cdot i_{s q}
$$

and solving for the speed derivative:

$$
\frac{d \omega_{m}}{d t}=\frac{3}{2 J_{m}} p \psi_{m} \cdot i_{s q}-\frac{1}{J_{m}} T_{L}-\frac{B_{m}}{J_{m}} \omega_{m} .
$$

The second order derivative of the speed is obtained by derivation of equation (7),

$$
\frac{d^{2} \omega_{m}}{d t^{2}}=\frac{3}{2 J_{m}} p \psi_{m} \frac{d i_{s q}}{d t}-\frac{1}{J_{m}} \frac{d T_{L}}{d t}-\frac{B_{m}}{J_{m}} \frac{d \omega_{m}}{d t} .
$$


The second order Taylor discretization of the mechanical speed is then:

$$
\omega_{m}^{k+1}=\omega_{m}^{k}+\left.T_{s \omega} \cdot \dot{\omega}_{m}\right|_{k}+\left.\frac{T_{s \omega}^{2}}{2} \cdot \ddot{\omega}_{m}\right|_{k},
$$

where the $T_{s \omega}$ is the downsampling period of the outer control loop. The derivative of the quadrature stator current in (8) is discretized with the forward-Euler method:

$$
\frac{d i_{s q}}{d t}=\frac{i_{s q}^{k+1}-i_{s q}^{k}}{T_{s \omega}} .
$$

Then, using equations (7), (8) and (10) in equation (9) and considering $\omega_{m}^{k+1}=\omega^{*}$ and $i_{s q}^{k+1}=i_{s q}^{*}$, where $\omega^{*}$ and $i_{s q}^{*}$ are the speed and quadrature current references respectively, and that the load torque is invariant in a sampling time, it is possible to solve equation (9) in order to obtain a quadrature stator current reference:

$$
\begin{aligned}
i_{s q}^{*}= & -\frac{1}{\left(J_{m}^{2} K_{T} T_{s \omega}\right)}\left(2 J_{m}^{2} \omega_{m}^{k}-2 J_{m}^{2} \omega^{*}+B_{m}^{2} T_{s \omega}^{2} \omega_{m}^{k}\right. \\
& +B_{m} \hat{T}_{L} T_{s \omega}^{2} p-2 B_{m} J_{m} T_{s \omega} \omega_{m}^{k}-2 J_{m} \hat{T}_{L} T_{s \omega} p \\
& \left.+i_{s q}^{k} J_{m}^{2} K_{T} T_{s \omega}-B_{m} i_{s q}^{k} J_{m} K_{T} T_{s w}^{2}\right)
\end{aligned}
$$

where $K_{T}=\frac{3 p^{2} \psi_{m}}{2 J_{m}}$.

The reference obtained in (11) is used as input in the inner control loop. Equation (11) needs an estimation of the load torque $\hat{T}_{L}$ to be calculated. For this reason a Kalman filter is used as a disturbance observer to estimate the load torque $T_{L}$. More details of the KF implementations have been reported by the authors in [16].

\section{B. Inner Control Loop}

The inner control loop corresponds to the electrical subsystem of the PMSM. Due to the discrete nature of the control platform, a discrete model of the PMSM, delivered in (3)-(4), is presented below using a second order Taylor discretization,

$$
\mathbf{x}^{k+1}=\mathbf{x}^{k}+\left.T_{s} \cdot \dot{\mathbf{x}}\right|_{k}+\left.\frac{T_{s}^{2}}{2} \cdot \ddot{\mathbf{x}}\right|_{k}
$$

where the second derivative of the state vector is obtained as,

$$
\ddot{\mathbf{x}}=\dot{f}(\mathbf{x}, \mathbf{u}),
$$

and where $T_{s}$ is sampling period of the inner control loop.

First, the system's response is predicted for each of the voltage vectors in the finite set of vectors produced by the power converter, assuming application of each vector for a complete sampling period $T s$. The current error produced is evaluated by the quadratic cost function (14), in which the objective is a current reference tracking in $d q$-frame. The active vector that minimizes the error $\left(v_{o p t}\right)$ and the active vector that produces the second smallest error $\left(v_{o p t}^{\prime}\right)$ are identified. It must be noted that $v_{o p t}$ and $v_{o p t}^{\prime}$ are always adjacent vectors.

$$
g\left(\mathbf{v}_{s, i}\right)=E_{d}^{2}\left(\mathbf{v}_{s, i}\right)+E_{q}^{2}\left(\mathbf{v}_{s, i}\right),
$$

with,

$$
E_{d}\left(\mathbf{v}_{s, i}\right)=i_{d}^{*}-i_{d}^{p}\left(\mathbf{v}_{s, i}\right)
$$

$$
E_{q}\left(\mathbf{v}_{s, i}\right)=i_{q}^{*}-i_{q}^{p}\left(\mathbf{v}_{s, i}\right),
$$

where $i_{d}^{*}$ and $i_{q}^{*}$ are the direct and quadrature current references, respectively. $\mathbf{v}_{s, i}$ is the voltage vector of the $2 \mathrm{~L}$ VSI, with $i \in\{0, \ldots, 7\} . i_{d}^{p}\left(\mathbf{v}_{s, i}\right)$ and $i_{q}^{p}\left(\mathbf{v}_{s, i}\right)$ are the direct and quadrature current predictions based on the load model, respectively.

\section{Modulated Model Predictive Control}

The two active vectors $v_{o p t}, v_{o p t}^{\prime}$ with zero vector $v_{0}$ are used to synthesize the optimal voltage actuation for the next sampling period time. By modulating between these three voltage vectors, the current error can be made to average zero in a single sampling period, [14]. Then, the problem is reduced to obtaining the three times for which each of the respective three voltage vectors must be applied to average zero current error, $\tau_{j}$ with $j \in\{0,1,2\}$. For this, the following system of equations must be solved,

$$
\begin{cases}\sum_{j=0}^{2} & \tau_{j} \cdot E_{d, j}=0 \\ \sum_{j=0}^{2} & \tau_{j} \cdot E_{q, j}=0 \\ \sum_{j=0}^{2} & \tau_{j}=T_{s}\end{cases}
$$

where $E_{d, j}$ and $E_{q, j}$ are the errors in the $d$ and $q$ axis as defined in (15) and (16), produced by the zero vector $\left(v_{0}\right)$, the optimum vector $\left(v_{\text {opt }}\right)$ and the second optimum vector $\left(v_{o p t}^{\prime}\right)$, as obtained with the cost function (14).

Solving (17), the three times are obtained:

$$
\begin{aligned}
& \tau_{0}=T_{s} \frac{E_{d, 1} E_{q, 2}-E_{d, 2} E_{q, 1}}{D}, \\
& \tau_{1}=T_{s} \frac{E_{d, 2} E_{q, 0}-E_{d, 0} E_{q, 2}}{D}, \\
& \tau_{2}=T_{s} \frac{E_{d, 0} E_{q, 1}-E_{d, 1} E_{q, 0}}{D},
\end{aligned}
$$

where,

$$
\begin{aligned}
D= & E_{d, 0} E_{q, 1}-E_{d, 1} E_{q, 0}-E_{d, 0} E_{q, 2}+E_{d, 2} E_{q, 0} \\
& +E_{d, 1} E_{q, 2}-E_{d, 2} E_{q, 1} .
\end{aligned}
$$

Where sub-indexes 0,1 and 2 refere to the zero vector $\left(v_{0}\right)$ and to the optimum vector $\left(v_{o p t}\right)$ and the second optimum vector $\left(v_{o p t}^{\prime}\right)$ found optimizing the value of the cost function (14).

\section{Simulation Results}

The simulations of this work were performed using the software PLECS. The parameters of the permanent-magnet synchronous machine used are presented in Table I. The inner control loop of the modulated model predictive speed control runs at a sampling time of $T_{s}=50[\mu \mathrm{s}]$, while the outer speed loop it is subsampled by a factor of eight, i.e. $T_{s \omega}=400[\mu \mathrm{s}]$. The pulse-width modulation (PWM) has a carrier frequency 
Finite-Set Model Predictive Speed Control (a)

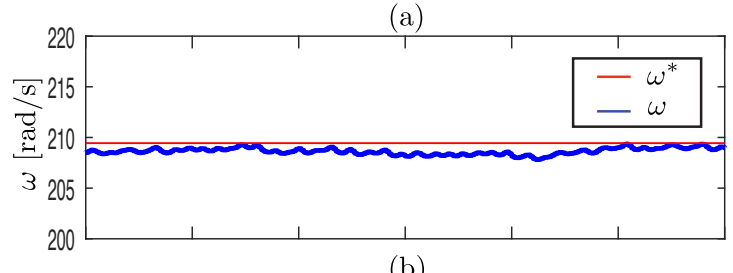

(b)

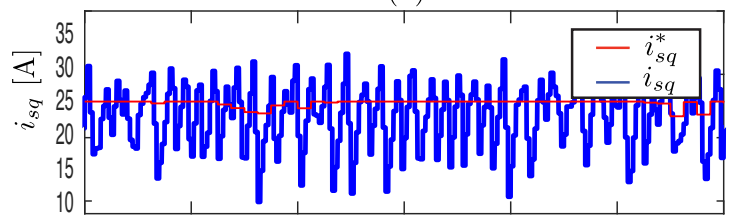

(c)

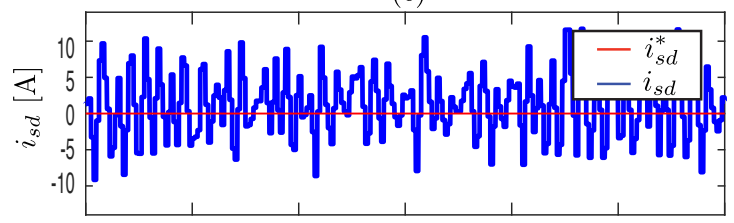

(d)

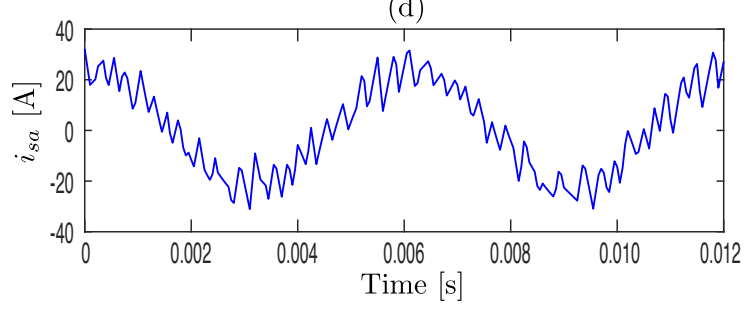

Modulated Model Predictive Speed Control

(e)

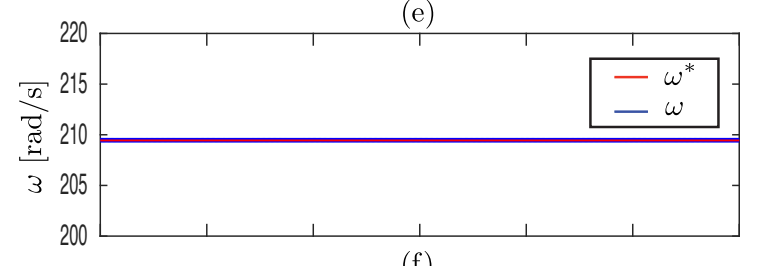

(f)

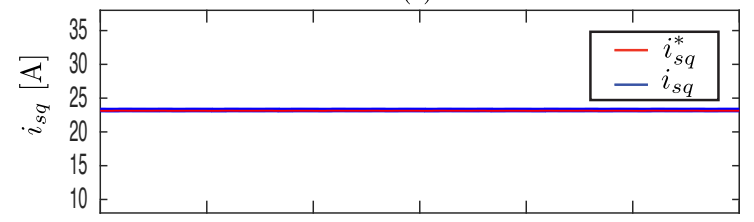

$(\mathrm{g})$

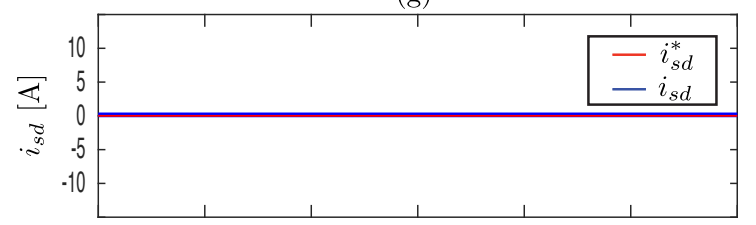

(h)

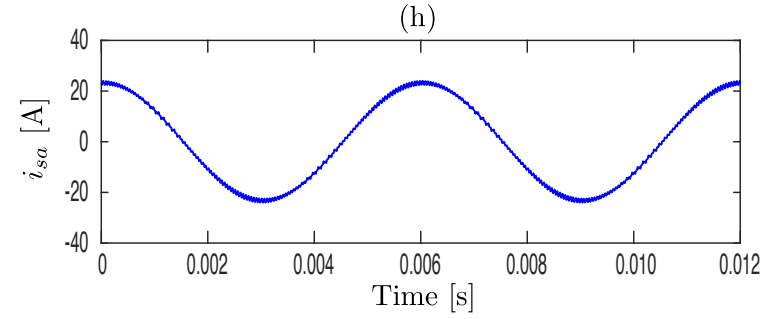

Fig. 3. Steady-state condition: (a)-(e) Motor speed $\omega$ and reference speed $\omega^{*}$; (b)-(f) Quadrature stator current $i_{s q}$ and reference quadrature stator current $i_{s q}^{*}$; (c)-(g) Direct stator current $i_{s d}$ and reference direct stator current $i_{s d}^{*}$; (c)-(h) Phase- $a$ stator current $i_{s a}$.

TABLE I

PARAMETERS

\begin{tabular}{c|cc} 
Parameter & Value & Unit \\
\hline \hline$R_{s}$ & 0.369 & {$[\Omega]$} \\
$L_{s}$ & 2.4 & {$[\mathrm{mH}]$} \\
$\psi_{m}$ & 0.129 & {$[\mathrm{~Wb}]$} \\
$J_{m}$ & $1.916 \cdot 10^{-3}$ & {$\left[\mathrm{Kg} \cdot \mathrm{m}^{2}\right]$} \\
$B_{m}$ & $4.64 \cdot 10^{-3}$ & {$\left[\mathrm{Nm} \cdot \frac{\mathrm{rad}}{\mathrm{s}}\right]$} \\
$p$ & 5 &
\end{tabular}

of $f_{s w}=10 \mathrm{kHz}$. The proposed method is compared to the related finite-set model predictive speed control (FS-MPSC) as previously proposed in [16]. In this case, the inner FSMPSC current loop runs at $T_{s}=17[\mu s]$.

The steady-state behavior of the proposed control scheme is presented in Fig. 3. The steady-state condition considers a nominal reference speed and $90 \%$ of the load torque. The results of the proposed method are the ones on the right, while FS-MPSC results are the ones on the left. The proposed method has an excellent tracking of the reference speed, without an observable ripple and stationary error, as shown in Fig. 3(e). The current control of this method (Fig. 3(f) and Fig. 3(g)) also has good performance. The phase- $a$ stator current has sinusoidal-waveform without distortion. FS-MPSC results, shown on the right, also achieve the speed control objectives, however, they have significant ripple around their current references. This produce a distortion in the phase- $a$ stator current, as it is shown Fig. 3(d).

Fig. 4 shows the performance of the current tracking in $\alpha \beta$ frame for both methods. The result for the proposed MMPSC is shown in Fig. 4(b), where its excellent performance is evident. Fig. 4(a) presents the behavior of the FS-MPSC, the method achieves the a current with average value tracking the reference, however, its performance has an evident a large switching ripple.

The harmonic spectrum of phase- $a$ stator current is presented in Fig. 5. Fig. 5(b) shows the spectrum of the MMPSC strategy, where concentrated spectral lines around of carrier frequency $\left(f_{s w}=10 \mathrm{kHz}\right)$ and its multiples are observable. The spectrum for the FS-MPSC method is presented in Fig. 5(a). This shows a switching harmonic spectrum that is distributed, which is typical of FS-MPC strategies. The total harmonic distortion (THD) for MMPSC is only $3.2 \%$, while the THD of the FS-MPSC is $23.1 \%$.

The dynamic behavior for the proposed control method is evaluated in a speed reversal from the nominal speed to negative nominal speed with a constant load torque of $90 \%$ applied all the time. The speed control shows good reference tracking, as it is shown in Fig. 6(e). Notable is that MMPSC achieves the negative reference speed at the 

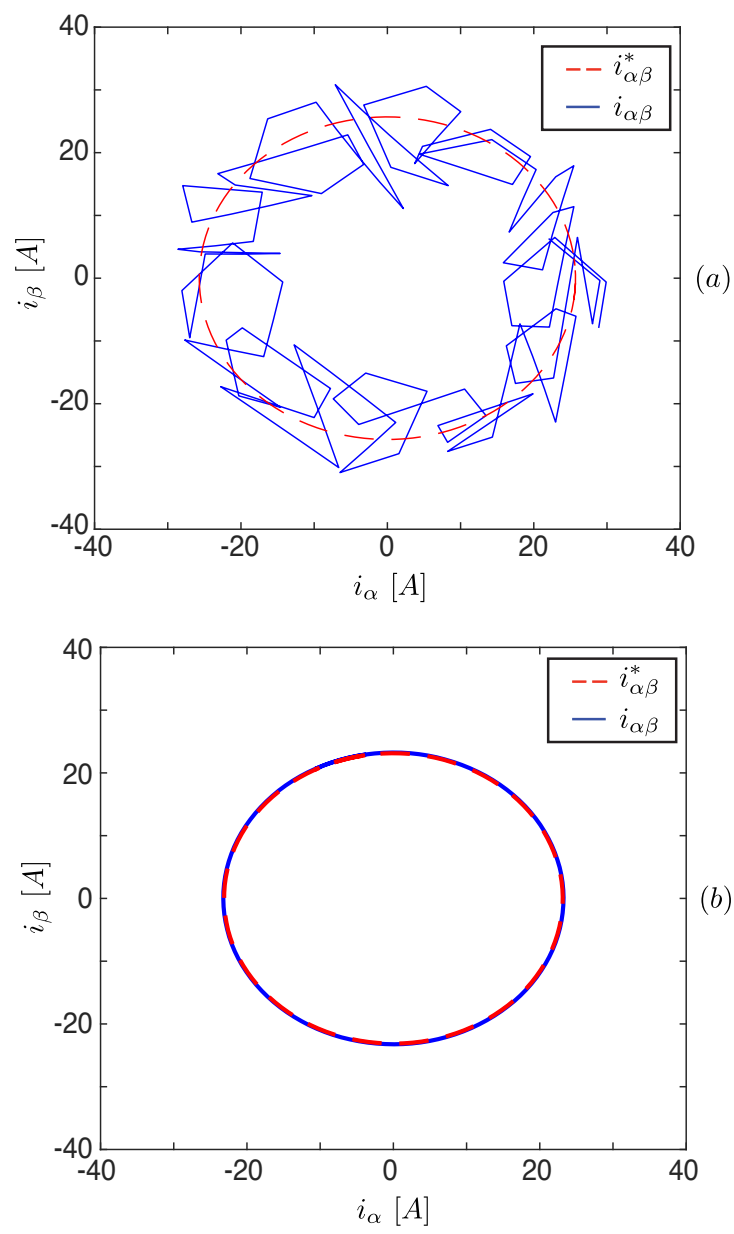

Fig. 4. Current behavior in $\alpha \beta$-frame: (a) Finite-set model predictive speed control; (b) Modulated model predictive speed control.

same time than FS-MPSC (Fig. 6(a)), demonstrating its fastdynamic response. Respect to the current control variables, the proposed method shows a clear performance advantage at all the time, with minimum ripple and no low frequency oscillations.

\section{CONCLUSIONS}

This paper presented a modulated model predictive speed control for a permanent-magnet synchronous machine. The method used a finite-set model predictive control principle to identified the optimal voltage vectors to be applied but uses PWM modulation to achieve zero average current error within one modulation period.

The control strategy proposed achieves fixed switching frequency, no steady-state speed error thanks to the use of a load torque observer and fast dynamic response due to the predictive model nature.

Simulation results have been presented to validate the proposed strategy. The steady-state performance is excellent, with minimum switching ripple, characteristic of PWM converter and without low frequency distortion or steady state error, obtaining a sinusoidal-waveform of the stator current
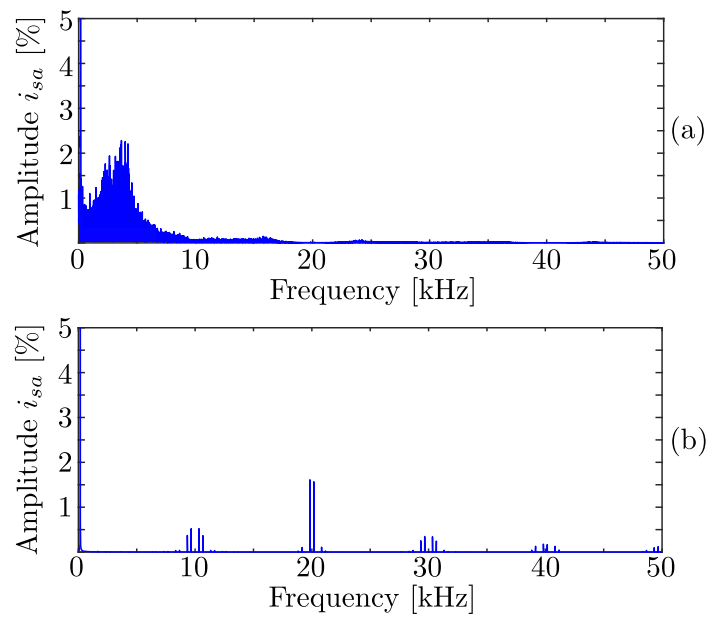

Fig. 5. Harmonic spectrum of stator current $i_{s a}$ of: (a) Finite-set model predictive speed control; (b) Modulated model predictive speed control.

with a total harmonic distortion of the $3.2 \%$. The most important result is that the speed dynamic response achieves the same performance previously reported FS-MPC strategies, but without their well documented disadvantages in terms of current switching ripple.

\section{ACKNOWLEDGMENT}

The authors acknowledge the support provided by the Chilean National Fund of Scientific and Technological Development (FONDECYT) under Grant 1170167.

\section{REFERENCES}

[1] S. Vazquez, J. I. Leon, L. G. Franquelo, J. Rodriguez, H. A. Young, A. Marquez, and P. Zanchetta, "Model predictive control: A review of its applications in power electronics," IEEE Industrial Electronics Magazine, vol. 8, no. 1, pp. 16-31, March 2014.

[2] J. Rodriguez, M. P. Kazmierkowski, J. R. Espinoza, P. Zanchetta, H. Abu-Rub, H. A. Young, and C. A. Rojas, "State of the Art of Finite Control Set Model Predictive Control in Power Electronics,' IEEE Transactions on Industrial Informatics, vol. 9, no. 2, pp. 10031016, May 2013.

[3] S. Kouro, M. A. Perez, J. Rodriguez, A. M. Llor, and H. A. Young, "Model Predictive Control: MPC's Role in the Evolution of Power Electronics," IEEE Industrial Electronics Magazine, vol. 9, no. 4, pp. 8-21, dec 2015.

[4] Z. Zhang, C. M. Hackl, and R. Kennel, "Computationally efficient dmpc for three-level npc back-to-back converters in wind turbine systems with pmsg," IEEE Transactions on Power Electronics, vol. 32, no. 10, pp 8018-8034, Oct 2017.

[5] R. Baidya, R. P. Aguilera, P. Acuña, S. Vazquez, and H. d. T. Mouton, "Multistep model predictive control for cascaded h-bridge inverters: Formulation and analysis," IEEE Transactions on Power Electronics, vol. 33, no. 1, pp. 876-886, Jan 2018

[6] C. F. Garcia, M. E. Rivera, J. R. Rodriguez, P. W. Wheeler, and R. S. Pena, "Predictive Current Control With Instantaneous Reactive Power Minimization for a Four-Leg Indirect Matrix Converter," IEEE Transactions on Industrial Electronics, vol. 64, no. 2, pp. 922-929, feb 2017.

[7] A. Dekka, B. Wu, V. Yaramasu, and N. R. Zargari, "Model predictive control with common-mode voltage injection for modular multilevel converter," IEEE Transactions on Power Electronics, vol. 32, no. 3, pp. 1767-1778, March 2017.

[8] B. Fan, K. Wang, P. Wheeler, C. Gu, and Y. Li, "An optimal full frequency control strategy for the modular multilevel matrix converter based on predictive control," IEEE Transactions on Power Electronics, vol. 33, no. 8, pp. 6608-6621, Aug 2018. 
Finite-Set Model Predictive Speed Control

(a)

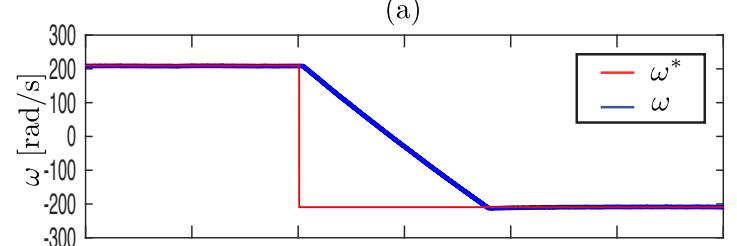

(b)

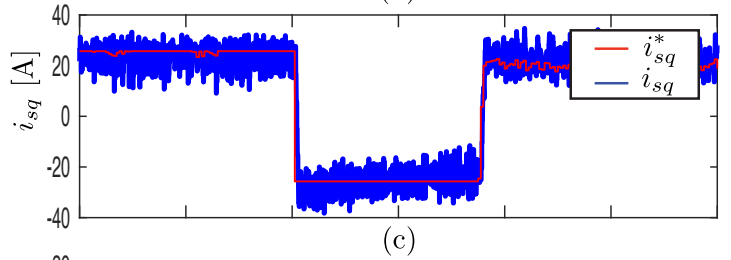

(c)

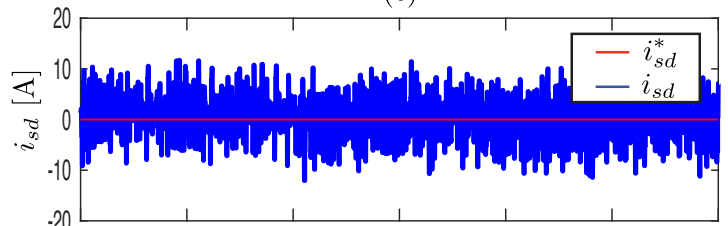

(d)

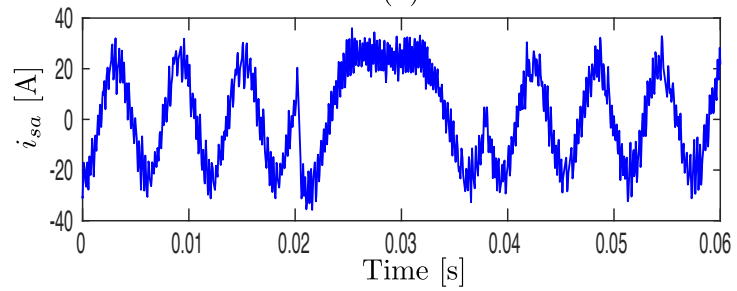

Modulated Model Predictive Speed Control

(e)

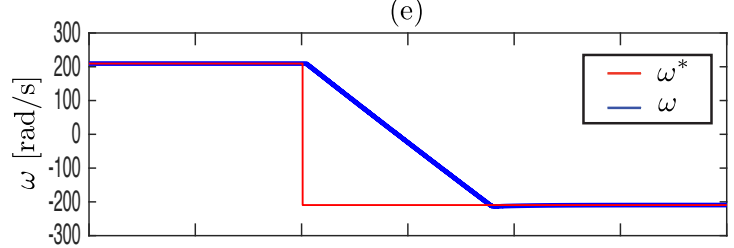

(f)

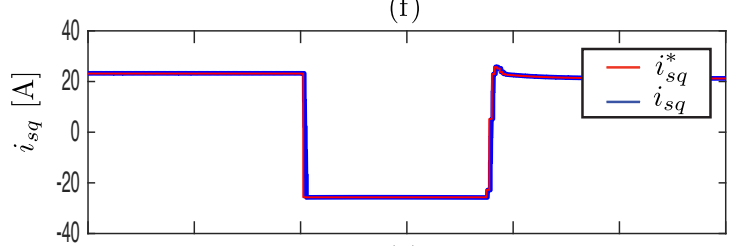

(g)

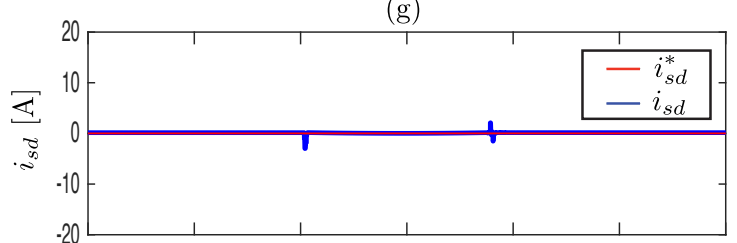

(h)

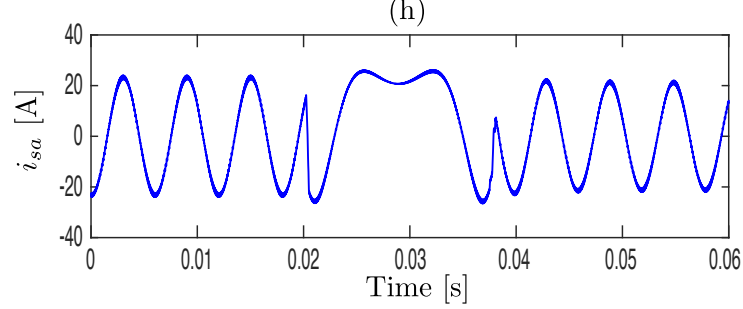

Fig. 6. Dynamic response during a step-change in reference speed: (a)-(e) Motor speed $\omega$ and reference speed $\omega^{*}$; (b)-(f) Quadrature stator current $i_{s q}$ and reference quadrature stator current $i_{s q}^{*}$; (c)-(g) Direct stator current $i_{s d}$ and reference direct stator current $i_{s d}^{*}$; (c)-(h) Phase- $a$ stator current $i_{s a}$.

[9] F. Wang, X. Mei, J. Rodriguez, and R. Kennel, "Model predictive control for electrical drive systems-an overview," CES Transactions on Electrical Machines and Systems, vol. 1, no. 3, pp. 219-230, September 2017.

[10] T. Geyer, "Model Predictive Direct Current Control: Formulation of the Stator Current Bounds and the Concept of the Switching Horizon," IEEE Industry Applications Magazine, vol. 18, no. 2, pp. 47-59, Mar. 2012.

[11] M. Amiri, J. Milimonfared, and D. A. Khaburi, "Predictive torque control implementation for induction motors based on discrete space vector modulation," IEEE Transactions on Industrial Electronics, vol. 65, no. 9, pp. 6881-6889, Sept 2018.

[12] E. Fuentes and R. M. Kennel, "A finite-set model predictive position controller for the permanent magnet synchronous motor," in 2013 IEEE International Symposium on Sensorless Control for Electrical Drives and Predictive Control of Electrical Drives and Power Electronics (SLED/PRECEDE). IEEE, oct 2013, pp. 1-7.

[13] A. Formentini, A. Trentin, M. Marchesoni, P. Zanchetta, and P. Wheeler, "Speed Finite Control Set Model Predictive Control of a PMSM Fed by Matrix Converter,' IEEE Transactions on Industrial Electronics, vol. 62, no. 11, pp. 6786-6796, nov 2015.

[14] E. Fuentes, C. A. Silva, and R. M. Kennel, "Mpc implementation of a quasi-time-optimal speed control for a pmsm drive, with inner modulated-fs-mpc torque control," IEEE Transactions on Industrial Electronics, vol. 63, no. 6, pp. 3897-3905, June 2016.

[15] A. Darba, F. De Belie, P. D'haese, and J. A. Melkebeek, "Improved Dynamic Behavior in BLDC Drives Using Model Predictive Speed and Current Control," IEEE Transactions on Industrial Electronics, vol. 63, no. 2, pp. 728-740, feb 2016.

[16] C. Garcia, J. Rodriguez, C. Silva, C. Rojas, P. Zanchetta, and H. AbuRub, "Full Predictive Cascaded Speed and Current Control of an Induction Machine," IEEE Transactions on Energy Conversion, vol. 31, no. 3, pp. 1059-1067, sep 2016

[17] L. Tarisciotti, A. Formentini, A. Gaeta, M. Degano, P. Zanchetta, R. Rabbeni, and M. Pucci, "Model predictive control for shunt active filters with fixed switching frequency," IEEE Transactions on Industry Applications, vol. 53, no. 1, pp. 296-304, Jan 2017.

[18] L. Tarisciotti, P. Zanchetta, A. Watson, J. C. Clare, M. Degano, and S. Bifaretti, "Modulated model predictive control for a three-phase active rectifier," IEEE Transactions on Industry Applications, vol. 51, no. 2, pp. 1610-1620, March 2015.

[19] S. Vazquez, A. Marquez, R. Aguilera, D. Quevedo, J. I. Leon, and L. G. Franquelo, "Predictive optimal switching sequence direct power control for grid-connected power converters," IEEE Transactions on Industrial Electronics, vol. 62, no. 4, pp. 2010-2020, April 2015.

[20] E. Fuentes, C. A. Silva, and R. M. Kennel, "Mpc implementation of a quasi-time-optimal speed control for a pmsm drive, with inner modulated-fs-mpc torque control," IEEE Transactions on Industrial Electronics, vol. 63, no. 6, pp. 3897-3905, June 2016.

[21] C. F. Garcia, C. A. Silva, J. R. Rodriguez, P. Zanchetta, and S. A. Odhano, "Modulated model predictive control with optimized overmodulation," IEEE Journal of Emerging and Selected Topics in Power Electronics, pp. 1-1, 2018. 